\title{
Proliferation of Multi-Cultures Through Globalization: Is It Promoting the Indigenous Culture or Global Culture?
}

\author{
Ayesha Saddiqa ${ }^{1}$, Maria Isabel Maldonado Garcia ${ }^{1} \&$ Nadir $_{\text {Ali }}{ }^{1}$ \\ ${ }^{1}$ Department of English Language and Literature, University of Management and Technology Lahore, Pakistan \\ Correspondence: Dr. Nadir Ali, Naseem Medical Centre, 254-Main Outfall Road Sanat Nagar, Islampura, Lahore, \\ Punjab, Pakistan. E-mail: dr_nadir_ali@yahoo.com
}

Received: December 16, 2018 Accepted: January 19, 2019 Online Published: February 24, 2019

doi:10.5539/ijel.v9n2p75

URL: https://doi.org/10.5539/ijel.v9n2p75

\begin{abstract}
The purpose of the study was to highlight the impact of multicultural proliferation through globalization on the adolescents of Lahore, Pakistan. A way to measure part of the impact is to have an understanding of how they have internalized foreign holidays and/or festivals which belong to other cultures. The data were collected from 200 male and female participants, of ages 13 to 19 years. The sample was subdivided into two groups of 100 participants each based on their parents' income level and the type of their institution (public or private). The medium of instruction in the private institutions of Lahore is English. English is, clearly, the language of globalization. In this regard, the hypothesis is that those students who study in private schools are more affected than those who study in public schools and whose medium of instruction is Urdu. A survey design was used to collect data regarding their perceptions about foreign cultural and religious festivals such as "Christmas", "Holi", "Valentine's Day", etc. Hamelink's Cultural synchronization theory provided the theoretical lens to the study. The analysis procedure was based on content analysis. The findings reveal a vivid difference between the perceptions of both groups. The adolescents who belong to the lower socio-economic status (who attend public schools) do not favour the celebration of foreign festivals. However, a tendency towards celebrating "Black Friday", "Valentine's Day" and "Basant" has been noticed. On the other hand, the adolescents of higher socio-economic background (who attend private schools) look forward to celebrating these festivals and perceive their celebration does not harm their cultural values. Even if this effect is partially due to globalization, the speedy influence on one stratum of the young generation of Pakistan may lead to a rapid assimilation to the global culture in the forthcoming times and also an opposition to the other strata. The study suggests a national media campaign as well as an institutional policy with an emphasis on indigenous cultural, social and religious values. There is a need to be more tolerant towards "others", and know how to co-exist but at the same time be able to retain the elements of the home culture of Pakistan, rather than adopting foreign practices.
\end{abstract}

Keywords: cultural invasion, festivals, globalization, multi-cultures, Pakistani teenagers

\section{Introduction}

Pakistan is a multi-cultural, multi-lingual and multi-ethnic country. It values the heritage offered by diverse cultures. This diversity has often been regularized by a superior power, i.e., religion or the government under the umbrella of Islam; due to these, Pakistani people seem to forget their cultural, linguistic, ethnic, social and geographical differences. This heritage united people in their struggle for the creation of Pakistan, as well as later, whenever they were assaulted (physically or ideologically) by any foreign or indigenous power. Initially, it had been only due to immigration that different cultures came into contact with each other, resulting into the clash of cultures in the form of ghettos, riots, class inequality, terrorist activities and discrimination in employment opportunities. However, due to the scientific revolutions in the field of information technology, there is another frontier which nations have to face now. The hybrid interaction, the twenty-four-hour contact with the outer world through cable and internet, trade across the globe, tourism, investment, and increasing mobility (Matos, 2012) are other forms of cultural contact in the $21^{\text {st }}$ century, playing a major role in dismantling the national barriers. The English language makes it easier. As a consequence of rapid media globalization and expanding multiculturalism, there is a proliferation of multi-cultures (as people are more in contact with the cultures of "others") extensively, which is the focus of the current study. This propagation of foreign cultures may be causing a risk to the indigenous cultural identity of people. It seems that globalization is restructuring the traditional values and cultural activities while blurring the differences between the native and the foreign culture 
(Gordon \& Meunier, 2001). There are numerous studies conducted across the globe such as in Turkey, France, India, Nigeria, Azerbaijan, China, etc., which underscore the potential impact of foreign cultures on the native culture, particularly, on the practices of the youth (Kaul, 2012; Kerimova, 2009; Yousaf, 2013) and highlight the same concern of the researchers across the globe, accentuating the need for the current study in the Pakistani scenario. This study explores the potential impact of globalization in the area of cross-cultural and cross-religious holidays.

\subsection{The Statement of Problem}

The case of Pakistan is not an exception in this regard. On the wings of technology, multi-cultures are flourishing, seemingly lifting previous cultural bars. People are exposed to a global culture (Sohail, 2015). Not only has globalization turned the world into a multicultural village, but people are making their own villages globally. Given the globalized nature of the modern world, one cannot stop the infiltration of technology, and the Western ideologies that accompany it. In recent years, Pakistan has seen an outburst of the celebration of festivals from around the world, mostly those of western cultures, whereas some are hauled from neighboring countries, particularly India. The present study intends to analyze the variety of perceptions, in regard to the celebration of these festivals. In an average Pakistani home, even an uneducated woman can receive ideas about how to decorate her house in Indian, American or British fashions by just switching on her television. Small children imitate the language (Saddiqa, 2017; Chaudhry, 2017), not only catchy lines but also the tone and multilingual accent of their favorite heroes, their dress codes, walking styles and, in short, the whole lifestyle by only watching foreign cartoons (Raza, Awan, \& Gondal, 2016; Sezer, 2016). People send wishes to their foreign social media friends on Christmas, Diwali, etc. all over the world and know when a specific event is approaching. Users change their display pictures on their social media accounts just to show their support to any cause or under the influence of the youth around the globe. Every other day, debates over "Black Friday" or "Blessed/Bright Friday", "Halloween Party" or "Hollow/Devil Party", arise, or whether to greet "Merry Christmas" or not, as if these are matters of life and death. It seems these are issues of identity and native cultures - perhaps the life or death of the culture of a nation — which need an in-depth analysis.

Given the nature of the now-globalized world, the permeation of modern technology, and the Western ideas that complement it, is unpreventable and has been further aided by the common language, English. The present study intends to analyze the variety of perceptions in regard to the celebration of these festivals. The argument that the study engages in, is that on the wings of globalization, as well as in the name of enlightenment and tolerance towards multi-cultures, Pakistan seems to be moving towards "assimilation" rather "integration". Globalization promotes a global culture which is overpowering the native culture. As an example, Pakistani people seem to suffer from a seasonal craze about the celebration of "Valentine's day" during which markets become full of heart-shaped balloons, red clothing and shoe brands display red shoes.

Another one of these foreign events is "Black Friday", with heavy advertisement through text messages and bill boards; it includes people's zest over shopping and outing, and is much criticized by the media. Time and again, pictures appear on social media showcasing people celebrating "Holi" in private parties. Children bring several invitations for Halloween parties and insist upon attending them. There are recorded instances where private schools in Lahore sent circulars to the parents demanding children to attend school in proper Halloween attire for celebration. Markets become full of costumes and accessories. The grand shopping malls of Lahore also arrange mega shows while decorating the premises in red on Valentine's Day and creepy corners on Halloween. The welcoming reception by the public on these events suggests that the Pakistani youth seems more fascinated by the purposively attractive display of multi-cultures through media. On the contrary, being multicultural demands of them to be more tolerant towards the "others" and know how to co-exist while equally be able "to retain the elements of their home culture" (Rattansi, 2011, p. 8) rather than adopt the foreign practices. In the light of the above scenario, the current study aims to outline the recent trends in Pakistani adolescents when it comes to the celebration of foreign cultural and religious festivals.

The study is significant in understanding the impact of propagation of multicultural festivals through globalization on Pakistani adolescents and endeavors to highlight the patterns of the adolescents' perception about celebrating foreign cultural and religious festivals. The perceptions of adolescents are significant in this regard as they are the ones who will lead the future of the country. The study also delineated the forces such as educational institutes, media or friends, which may be behind the introduction of these global multicultural activities to the young generation.

The study can be helpful in strategizing cultural policies, curriculum and the media to address the potential impact on our society. 


\subsection{Research Questions}

1) What are the recent trends that Pakistani adolescents follow regarding the celebration of foreign religious and cultural festivals?

2) Are they aware of their historical and religious significance?

3) Do parents allow their children to celebrate these foreign festivals or not?

4) How do adolescents learn about the foreign festivals?

5) What are the implications of multicultural festival exposure through globalization?

\section{Literature Review}

\subsection{The Concept of Festivals and Cultural Identity}

Culture is the complete code of life for a society and it is handed down from generation to generation. According to the Oxford Dictionary (2018), a festival is a day or period of celebration, typically for religious reasons, with its own social activities. During the course of history, some meaningful happenings come, which prove to be landmarks for the survival and growth of the societal structure. People record them and organize some activities or rituals to acknowledge their significance, which are repeatedly performed year after year and handed down from generation to generation. "The heart of every festival is a place and a place-based community actively reproducing their shared values and belief systems, there is an important sense in which these cultural meanings are intentionally produced to be read by the outside world" (Derrett, 2008). He also concludes that the celebration of these festivals facilitates community building, community integration and community cohesion; therefore, giving birth to a cultural identity that provides the members of the society with a sense of membership in one or more of the groups. Like everything else, this identity is also influenced by and experiences the impact of its surroundings, which produce a sense of loss at a cultural level. This may occur as a result of a cultural invasion due to cultural contact which has happened previously as a result of immigration and invasions or currently due to technological advancement and globalization.

The Pakistani society has also experienced cultural contact situations for centuries; initially, when Muslims lived in the Subcontinent and left their culture and religion, and later, due to the British colonization. In the 21st century, globalization is posing the same challenges. The youth seems to accept and adopt foreign ideas and values, whereas their parents, who believe in the cultural values once so dear to them, are wrecked by the young generation's adaptation to the perhaps not new, but foreign, trends which may be termed as a clash of generations.

\subsection{Globalization, Multicultural Activities \& Religious and Cultural Identity}

The discussion of global cultures versus local cultures, as well as multiculturalism, raises the issues of identity as "local culture" which usually resonates with identity-based culture. Nations remain no more the only source or donor of identity. The momentum of proliferation of multi-cultures through globalization raises the question of the national issue (Blanc-Noël, 2010), which is criticized by many scholars as a "cultural invasion". Hughes (1994) opines that "Culture and History are full of borders but they are all to some degree permeable". This explosion of multi-cultures is not devoid of the arguments of modernization rather westernization (Matos, 2012). It further criticizes its assaults on religious norms. In this regard, Keaney (2002) asserts that "globalization is stabbing the religious conviction and beliefs of masses by demeaning long-established and time-honoured ethics and supplanting the traditional values with the surfeit and covetousness prevalent in the West."

\subsection{Globalization and Mass Media}

Mass media is highly boosted and significantly advanced in recent times due to the revolutionary technologies of globalization, such as computerization, digitalization, satellite communications, fiber optics \& the Internet. Everything on media seems to be more international than local or national. Even cultural displays, whether economic, social, cultural or religious, are majorly global in their essence. People five oceans apart are able to watch ceremonies, matches, etc., being held in any corner of the world. A large number of individuals are interconnected today and there is a free dissemination of thoughts, values and ideas across the boundaries, whereas it may be almost impossible to be done physically and regularly, frequently due to certain economic restrictions. However, the impact of globalization on culture is stirring much debate. Adams and Goldbard (2009) remark:

The impact of global media may be immediate or long term, cumulative or dynamic, deep rooted or simply influencing some basic values and thinking. Though, expressions like cultural invasion, cultural intolerance, cultural imposition, and enrichment of culture or cultural exchange needs to be properly defined in right 
context, spirit and perspective but the phenomenon of global media is here to stay. (p. 4)

\subsection{Globalization and Expanding Multiculturalism - a Positive or Negative Force?}

There is a divide of opinion on the multicultural practices offered by globalization. On one hand, openness to multicultural activities and behavior are encouraged as empowering people with open-mindedness, tolerance, creativity, better coordination and hence improvising their abilities to function and integrate in a multi-cultural and multi-lingual society (Appiah, 2006; Maddux \& Galinsky, 2009; Tadmor, Satterstrom, Jang, \& Polzer, 2012). It is pointed out that multicultural exposure bestows people with multiple perspectives and reduces prejudices, making them receptive, even, to foreign ideas. They find themselves easily and efficiently adaptable to diverse cultural conditions (Chao, Kung, \& Yao, 2015).

Contrary to that, it is equally discouraged on the grounds of corrupting or flouting native cultures, values, ethics, social judgments and resulting in disorders at an individual level, as well as a social one (Adair, Okumura, \& Brett, 2001). They assert that it is a threat to the autonomy and integrity of the native cultural identity. Higham (2000) states that, under the shield of diversity, multicultural policies lead to the homogenization of cultures. The risk of cultural uniformity is the prospective of unparalleled cultural integration, leading to global culture. This rampant flow of multi-cultures through globalization gives way to the apprehensions of loss of domestic cultures and identity (Khan \& Arif, 2009). Every country has its own policies or own ways of responding to a phenomenon. Krzysztofek (2002) discusses five different ways in which national cultures or various societies respond to the cultural globalization. Those include: "complete acceptance of global culture; total rejection of global culture; selective adaptation; hybridization; and cultural dualism and pluralism".

\subsection{Assimilation or Integration}

The proliferation of multi-cultures through globalization also raises the voice of assimilation versus integration. Multiculturalism in its essence promotes cultural diversity but does not support assimilation (Crowder, 2013; Grant, 2014). On the other hand, globalization is mainly criticized over leading to a future of homogeneity and unification.

\subsection{Cultural Homogenization-Global Culture}

The concept of globalization assumes the world to be one global village with one culture. Kaul (2012) remarks: "Globalization creates a global culture, in which the identity is amalgamated, that tends to bring a homogenous culture throughout the world" (Kaul, 2012, p. 341). He thinks that this globalization can both assist in propagating native culture globally or perhaps invading the native culture even in its native country, which poses challenges to countries across the world.

\subsection{Studies in Pakistani Context and Around the Globe}

Several studies have been conducted in Pakistan to outline the impact of Globalization on cultural identity. Mustafa, Mushtaq, Malik and Abbas (2015) realized that globalization was posing some religious and cultural challenges to Pakistani people and such of their values, so they conducted a study to gauge the role of media in the cultural globalization and hence, foreign cultural proliferation in Pakistan. They concluded that the exposure to new and foreign cultural and religious trends is leading towards the adoption of those values, which, resultantly, pose threats to the native cultural identity (Mustafa, Mushtaq, Malik, \& Abbas, 2015). These effects are not limited to just lifestyles or clothing. Rather, the national language also exhibits some foreign language impact. In this regard, Maldonado Garcia (2015) conducted a study where the impact of English upon Urdu was measured, as well as another study where the co-existence of Urdu and English in Pakistan was evaluated (Maldonado Garcia, 2016).

Kayani, Ahmad and Saeed (2013) also conducted a study to outline the impact of cultural globalization. They concluded that globalization was credited with introducing new job opportunities, better lifestyles, acknowledging and recognizing even a common man's voice through different media sources. However, unfortunately, there seems to be a decline in social, ethical, moral, cultural and traditional principles. The prevalent cultural trends in our youth are alienating them from their indigenous culture. Foreign ways of life, values and culture seem to challenge the "moral standards of local cultures" and hence their cultural identity promotes obscenity and negativity in peoples' minds (Kayani, Ahmad, \& Saeed, 2013, p.137).

Naz, Khan, Hussain and Daraz (2012) also conducted a study in Khyber Pakhtunkhwa, Pakistan to investigate the impact of globalization on the socio-cultural psychological identity of Pakhtuns. The findings revealed that they faced identity crises at grounds such as cultural, religious and psychological ones. Cultural plurality and diversity seemed to lead, in this case, to social disintegration. 
Not only Pakistani researchers, but also scholars from across the globe consider globalization and proliferation of multi-cultures a challenge for indigenous cultural identity and multiple studies have been conducted in several countries such as in Azerbaijan (Kerimova, 2009), Turkey (Dr. Yusuf Ornek, 2007), Nigeria (Yousaf, 2013), India (Kaul, 2012), France (Gordon \& Meunier, 2001), etc.

Ornek (2007), in his theoretical study, asserts that cultural diversity celebrated through globalization should not challenge the "traditional make-up" of local societies. He remarked that people of developing countries do not know how to retain their cultural identity, and, if globalization is not controlled nationally, then developing countries may enter an even worse phase in future.

Hence, globalization is leading to cultural, political, religious, social and economic transformations, thus, it seems to defy the already established cultural patterns, national identity and challenging the social order. There is a revolution in almost every walk of life, including dressing styles, food and cuisine, celebration of festivals, advertisements and media, traditions and tenets, home decor, relationships, birth or wedding announcements and much more. However, it is difficult to state whether this change is negative or positive. It depends more on the course of action it adopts and the patterns of change. The current study aims to underscore the challenges posed by globalization and attitudes of the public towards these trends. Do they accept it as something innovative, liberal, modernized and addressing to the new needs generated by the over-competitive world? Or do they look at it as a threat to their native culture, alienating their young generations from the traditions which once were a heritage to their forefathers? Though multiculturalism through globalization is revolutionizing almost all the realms of life, the study confines itself and examines the impact of multi-cultures proliferation through globalization (and the language of globalization) on the celebration of religious and cultural festivals only.

\section{Method}

\subsection{Theoretical Underpinning}

The study draws on the theory of "Cultural synchronization" proposed by Hamelink (1983). It implies that the indigenous culture is controlled and channelized by a powerful central nation according to their interests and desires (Hamelink, 1983). These decisions are later imposed with subtle but distressing efficiency on the dependent nations, without taking into consideration their needs. These multicultural or transnational practices then challenge the cultural integration of the dependent nation (Eisler, 2005). Hamelink (1983) proposed a new international order where he advocated national control over a country's information system as a basic necessity for national sovereignty. The current study stems from this theory of "Cultural synchronization" and argues that, if globalized media is leading to promote the global culture, hence posing threats to the indigenous cultural values, then it may arise the need for our government to take some substantial measures, where integration is encouraged while assimilation is highly discouraged. In this scenario, the chief agents of cultural synchronization in Pakistan are liberals, multinational companies, private institutions and international business chains, which need to operate under the national rules and regulations.

\subsection{Data Collection}

The research took place in Pakistan's metropolitan, Lahore. It is multi-cultural and multi-lingual as people migrate from different areas for reasons such as jobs, better education, improved life styles, etc. The population of the study was Lahore-based adolescents of ages between 13 to 19 years, both male and female. As Lahore is a cosmopolitan, there is enough representation of the diverse cultures of Pakistan, and most of the people across the country are Muslim, the data is considered to be representative and could be generalized over a larger population. The group was also further divided on the basis of their parents' income and their learning institution, public or private, to explore if any patterns existed in accordance with their socio-economic background and language of instruction - English in private schools and Urdu in public ones. The participants whose parents' income was up to 60,000/- PKR monthly and themselves were the students of public institutions formed one group (Group 1-A), and the second group (Group 1-B) was bracketed by students obtaining their education from private institutions whose parents' income was more than 60,000/- PKR per month. The reason for choosing these two groups was to see the patterns of peoples' perception in respect to their income. On the other hand, language plays a pivotal role in this case. Both groups are differently exposed to globalization. It is obvious that the level of exposure of those fluent in English language is larger than of those who do not understand English well, since they study with a different language (Urdu, which is not the language of globalization) as their medium of instruction.

The role of their educational institution should not be neglected in this respect. Pakistan happens to be a dichotomous society, wherein divisions and stratifications, in terms of classes, are intense on multiple platforms. The country is a rare example wherein there exist two dichotomous systems of education. Given the stark 
contrast of the curriculum being taught in these institutions, it is only natural that the end products (the students) of these institutions vary, not just in terms of their outlook, but also in terms of their perceptions, mindset and thinking patterns. Socio-economic conditions and affluence also direct their ways of leading their lives.

The researchers devised a questionnaire as the data collection tool. The data were collected from 200 participants; 100 participants from each group. This was followed by random one-to-one interviews of five participants from each group. The linguistics part of the study was performed through a "Content analysis" technique on the data following the six basic steps as offered by Berelson (1952), who defines content analysis as "a research technique for the objective, systematic and quantitative description of the manifest content of communication" (Berelson, 1952). However, it is not only a quantitative description, but also a qualitative one as Frisbie (1986) terms it. This technique will assist to analyze and define the data objectively and systematically and summarize the findings (Frisbie, 1986).

The data were divided into two parts; Group 1-A was composed of those who attended public school and whose parents' income was up to 60,000/- PKR and Group 1-B of those who attended private school and whose parents earned more than 60,000/- PKR per month.

Table 1. Demographics of the participants

\begin{tabular}{lllll}
\hline Sr. $\#$ & Age & Participants & Parents' income & Institution \\
\hline 1 & $13-19$ years & 100 & Up to $60,000 /-$ PKR & Public \\
2 & $13-19$ years & 100 & More than 60,000/- PKR & Private \\
\hline
\end{tabular}

\subsection{Cultural and Religious Festivals}

The researcher made a list of foreign religious and cultural festivals or events which are currently being celebrated in Pakistan in the light of media and present scenario. This list was obtained by asking the participants which festivals were celebrated in their schools. The following is the list of the festivals according to the response of the participants of the two groups.

According to the participants the foreign festivals most celebrated in Lahore are as follows:

Table 2. Foreign religious and cultural festivals

\begin{tabular}{lll}
\hline Christmas & New Year Eve & Halloween* \\
Easter & Black Friday & Valentine's Day \\
Diwali & Holi & Basant \\
\hline
\end{tabular}

Note. *Halloween in Pakistan is not celebrated in the "trick or treat" style by knocking on neighbours' doors. Rather, it is celebrated in schools by dressing in costumes for a party.

\section{Data Analysis and Findings}

\subsection{Part $A$}

In the first stage, the data collected through the questionnaire was analyzed statistically, in terms of frequency. The respondents were asked six questions and the data is presented below in the tabular form.

Table 3. The perceptions of the participants about question 1: Do you look forward to celebrating this day?

\begin{tabular}{clllllllllllllllllll}
\hline & \multicolumn{3}{l}{\begin{tabular}{l} 
Black \\
\multicolumn{3}{l}{ Friday }
\end{tabular}} & \multicolumn{3}{l}{ Valentine's } & New Year & Holi & & Christmas & Diwali & Easter & Basant & Halloween \\
\hline & $\mathrm{Y}$ & $\mathrm{N}$ & $\mathrm{Y}$ & $\mathrm{N}$ & $\mathrm{Y}$ & $\mathrm{N}$ & $\mathrm{Y}$ & $\mathrm{N}$ & $\mathrm{Y}$ & $\mathrm{N}$ & $\mathrm{Y}$ & $\mathrm{N}$ & $\mathrm{Y}$ & $\mathrm{N}$ & $\mathrm{Y}$ & $\mathrm{N}$ & $\mathrm{Y}$ & $\mathrm{N}$ \\
$1-\mathrm{A}$ & 76 & 24 & 58 & 42 & 21 & 79 & 02 & 98 & 01 & 99 & 00 & 100 & 00 & 100 & 64 & 36 & 09 & 91 \\
$1-\mathrm{B}$ & 82 & 18 & 92 & 08 & 87 & 13 & 67 & 33 & 52 & 48 & 00 & 100 & 04 & 96 & 49 & 51 & 68 & 32 \\
\hline
\end{tabular}

Note. Y=Yes; N=No; Group 1-A (age 13-19yrs, parents' income=up to 60,000/-PKR, studying in public institution); Group 1-B (age 13$19 \mathrm{yrs}$, parents' income $=$ more than $60,000 /$-PKR, studying in private institution).

The findings suggest that there is not much variation in the perceptions of participants who belong to the two groups about "Black Friday" and "Diwali". However, there is a stark difference evident in their responses about the celebration of "Halloween", "Christmas", "Holi" and "New Year's Eve". 


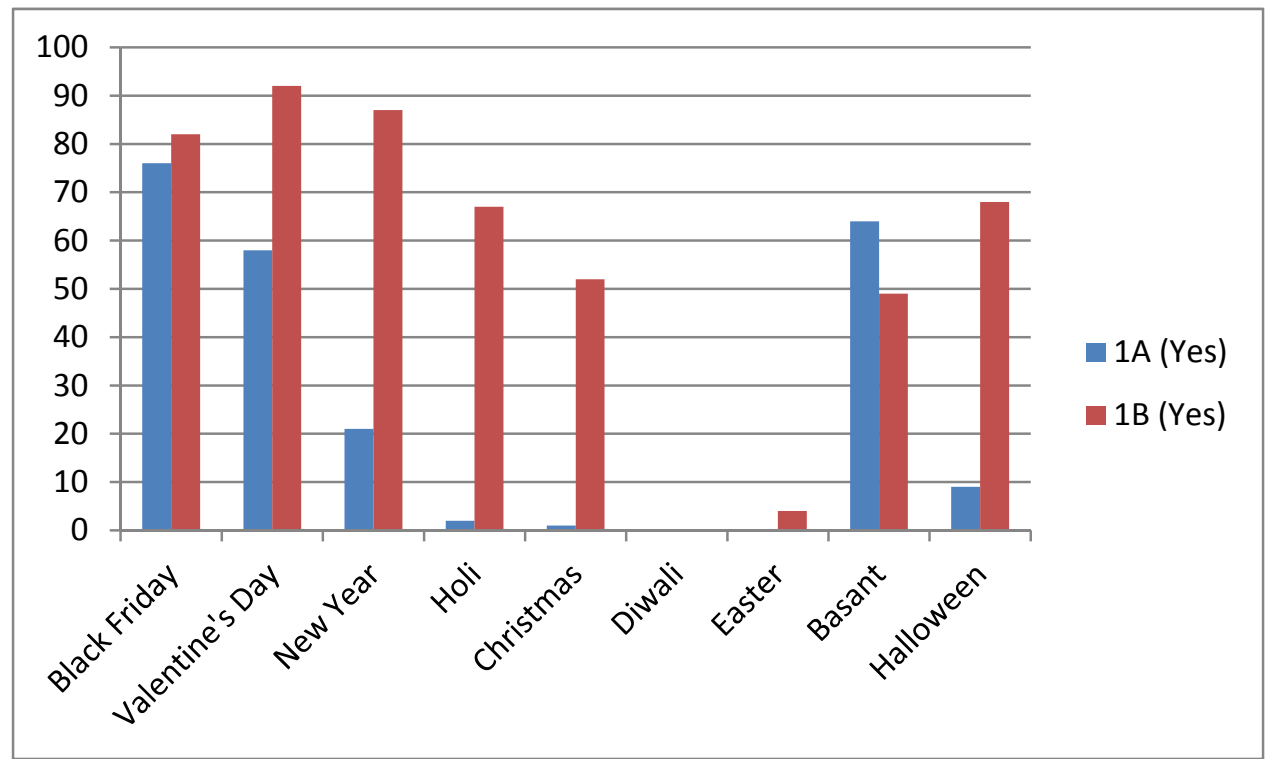

Figure 1. The number of participants from both groups who look forward to celebrating foreign festivals Note. Y-axis: The number of participants (Group 1-A \& Group 1-B); X-axis: Names of foreign festivals.

The participants who belong to the upper socio-economic class look forward to celebrating all these festivals, whereas the other group is only interested in celebrating "Black Friday", "Valentine's Day" and "Basant" which are non-religious holidays. Figure 1 is the graphical representation of the above-mentioned responses.

Table 4. The perceptions of the participants about question 2: Are you aware of the historical/religious significance of this day?

\begin{tabular}{|c|c|c|c|c|c|c|c|c|c|c|c|c|c|c|c|c|c|c|}
\hline & \multicolumn{2}{|c|}{$\begin{array}{l}\text { Black } \\
\text { Friday }\end{array}$} & \multicolumn{2}{|c|}{$\begin{array}{l}\text { Valentine's } \\
\text { Day }\end{array}$} & \multicolumn{2}{|c|}{ New Year } & \multicolumn{2}{|c|}{ Holi } & \multicolumn{2}{|c|}{ Christmas } & \multicolumn{2}{|c|}{ Diwali } & \multicolumn{2}{|c|}{ Easter } & \multicolumn{2}{|c|}{ Basant } & \multicolumn{2}{|c|}{ Halloween } \\
\hline & $\mathrm{Y}$ & $\mathrm{N}$ & $\mathrm{Y}$ & $\mathrm{N}$ & $\mathrm{Y}$ & $\mathrm{N}$ & $\mathrm{Y}$ & $\mathrm{N}$ & $\mathrm{Y}$ & $\mathrm{N}$ & $\mathrm{Y}$ & $\mathrm{N}$ & $\mathrm{Y}$ & $\mathrm{N}$ & $\mathrm{Y}$ & $\mathrm{N}$ & $\mathrm{Y}$ & $\mathrm{N}$ \\
\hline $1-A$ & 35 & 65 & 83 & 17 & 98 & 02 & 78 & 22 & 100 & 00 & 33 & 67 & 45 & 55 & 78 & 22 & 28 & 72 \\
\hline $1-B$ & 30 & 70 & 51 & 49 & 97 & 03 & 69 & 31 & 100 & 00 & 58 & 42 & 93 & 07 & 63 & 37 & 53 & 47 \\
\hline
\end{tabular}

Note. $\mathrm{Y}=\mathrm{Yes}$; N=No; Group 1-A (age 13-19yrs, parents' income=up to 60,000/-PKR, studying in public institution); Group 1-B (age 13$19 \mathrm{yrs}$, parents' income $=$ more than $60,000 /$-PKR, studying in private institution).

The findings suggest that most of the respondents do not know the religious or cultural significance of Black Friday and Halloween, though they look forward to celebrating them. On the other hand, they are much aware of the background of certain religious events such as "Valentine's Day", "New Year", "Holi", "Christmas", "Diwali", "Easter" and "Basant". 


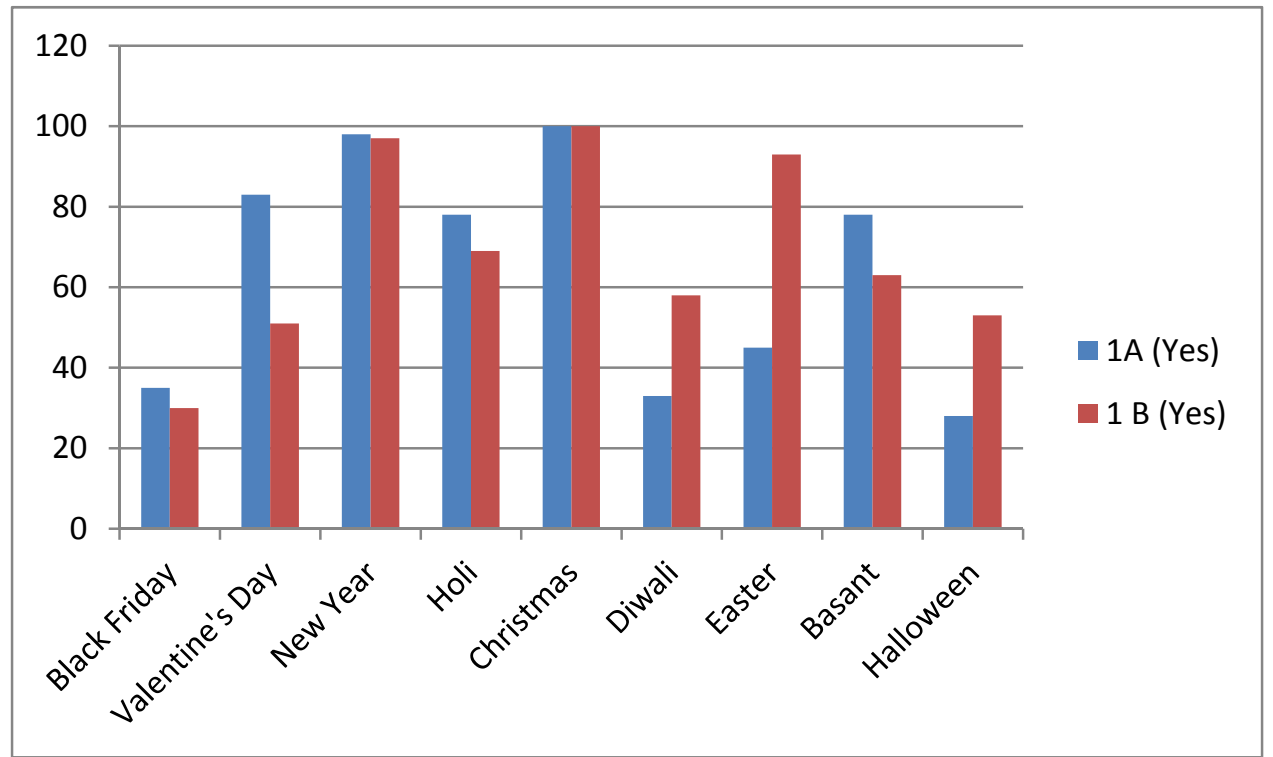

Figure 2. The participants who are aware of the religious/cultural significance of these festivals

Here, an important point needs to be mentioned, as the responses to question 1 reflect that Group 1-B is more interested in celebrating these foreign festivals, yet they are not conscious of their background. Figure 2 depicts the number of participants from both groups who are aware of the religious and cultural significance of these festivals.

Table 5. The perceptions of the participants about question 3: Do your parents allow you to celebrate this festival?

\begin{tabular}{|c|c|c|c|c|c|c|c|c|c|c|c|c|c|c|c|c|c|c|}
\hline & \multicolumn{2}{|c|}{$\begin{array}{l}\text { Black } \\
\text { Friday }\end{array}$} & \multicolumn{2}{|c|}{$\begin{array}{l}\text { Valentine's } \\
\text { Day }\end{array}$} & \multicolumn{2}{|c|}{ New Year } & \multicolumn{2}{|c|}{ Holi } & \multicolumn{2}{|c|}{ Christmas } & \multicolumn{2}{|c|}{ Diwali } & \multicolumn{2}{|c|}{ Easter } & \multicolumn{2}{|c|}{ Basant } & \multicolumn{2}{|c|}{ Halloween } \\
\hline & $\mathrm{Y}$ & $\mathrm{N}$ & $\mathrm{Y}$ & $\mathrm{N}$ & $\mathrm{Y}$ & $\mathrm{N}$ & $\mathrm{Y}$ & $\mathrm{N}$ & $\mathrm{Y}$ & $\mathrm{N}$ & Y & $\mathrm{N}$ & $\mathrm{Y}$ & $\mathrm{N}$ & $\mathrm{Y}$ & $\mathrm{N}$ & $\mathrm{Y}$ & $\mathrm{N}$ \\
\hline $1-\mathrm{A}$ & 88 & 12 & 07 & 93 & 05 & 95 & 00 & 100 & 00 & 100 & 00 & 100 & 00 & 100 & 65 & 35 & 05 & 95 \\
\hline $1-B$ & 94 & 06 & 75 & 25 & 63 & 37 & 57 & 43 & 42 & 58 & 26 & 74 & 38 & 62 & 78 & 22 & 89 & 11 \\
\hline
\end{tabular}

Note. $\mathrm{Y}=$ Yes; N=No; Group 1-A (age 13-19yrs, parents' income=up to 60,000/-PKR, studying in public institution); Group 1-B (age 13$19 \mathrm{yrs}$, parents' income $=$ more than $60,000 /$-PKR, studying in private institution).

The data show that parents of lower socio-economic adolescent group do not allow their children to celebrate such events with the exception of Black Friday and Basant. 


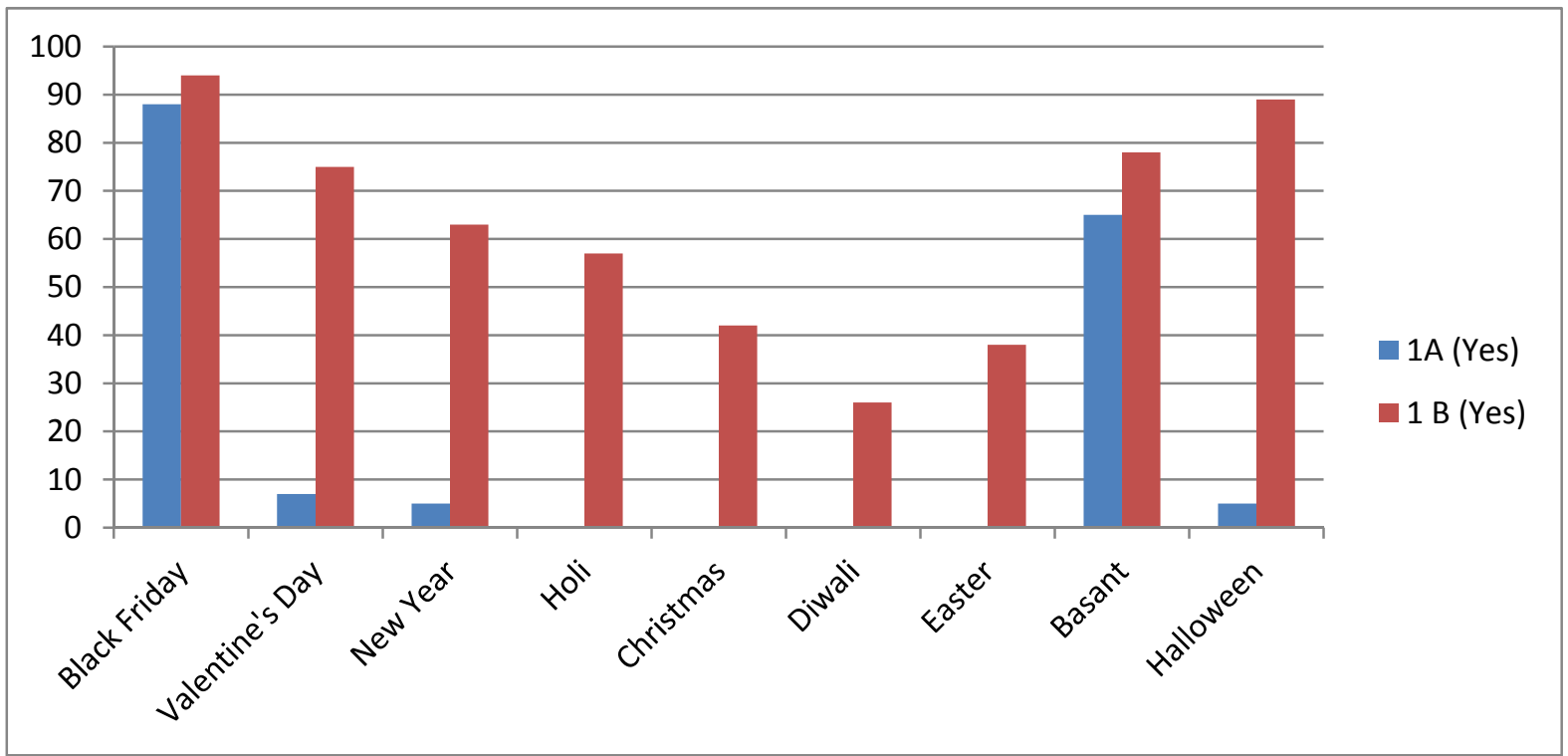

Figure 3. The number of participants whose parents allow them to celebrate these festivals

However, the parents of other groups have no problem with their children celebrating any festival as shown in Figure 3, the graphical representation of the participants' responses for the clear understanding of the readers.

Table 6. The perceptions of the participants about question 4: Is this day celebrated at your educational institution?

\begin{tabular}{|c|c|c|c|c|c|c|c|c|c|c|c|c|c|c|c|c|c|c|}
\hline & \multicolumn{2}{|c|}{$\begin{array}{l}\text { *Black } \\
\text { Friday }\end{array}$} & \multicolumn{2}{|c|}{$\begin{array}{l}\text { Valentine's } \\
\text { Day }\end{array}$} & \multicolumn{2}{|c|}{ New Year } & \multicolumn{2}{|c|}{ Holi } & \multicolumn{2}{|c|}{ Christmas } & \multicolumn{2}{|c|}{ Diwali } & \multicolumn{2}{|c|}{ Easter } & \multicolumn{2}{|c|}{ Basant } & \multicolumn{2}{|c|}{ Halloween } \\
\hline & $\mathrm{Y}$ & $\mathrm{N}$ & Y & $\mathrm{N}$ & Y & $\mathrm{N}$ & $\mathrm{Y}$ & $\mathrm{N}$ & $\mathrm{Y}$ & $\mathrm{N}$ & $\mathrm{Y}$ & $\mathrm{N}$ & Y & $\mathrm{N}$ & Y & $\mathrm{N}$ & Y & $\mathrm{N}$ \\
\hline $1-\mathrm{A}$ & 29 & 71 & 32 & 68 & 07 & 93 & 02 & 98 & 00 & 100 & 00 & 100 & 00 & 100 & 35 & 65 & 06 & 94 \\
\hline $1-B$ & 48 & 52 & 78 & 22 & 28 & 72 & 64 & 36 & 35 & 65 & 09 & 91 & 14 & 86 & 53 & 47 & 62 & 38 \\
\hline
\end{tabular}

Note. Y=Yes; N=No; Group 1-A (age 13-19yrs, parents' income=up to 60,000/-PKR, studying in public institution); Group 1-B (age 13-

$19 \mathrm{yrs}$, parents' income=more than 60,000/-PKR, studying in private institution). * In case of Black Friday: Are you in favour of the name "Black Friday"?

Regarding "Black Friday", 29 participants from group 1-A favored the name "Black Friday" whereas 71 participants said that they disliked the name (as we already know about the arguments regarding Black Friday/ Blessed Friday). On the other hand, 48 of the respondents from higher socio-economic background had no objection on its title. 


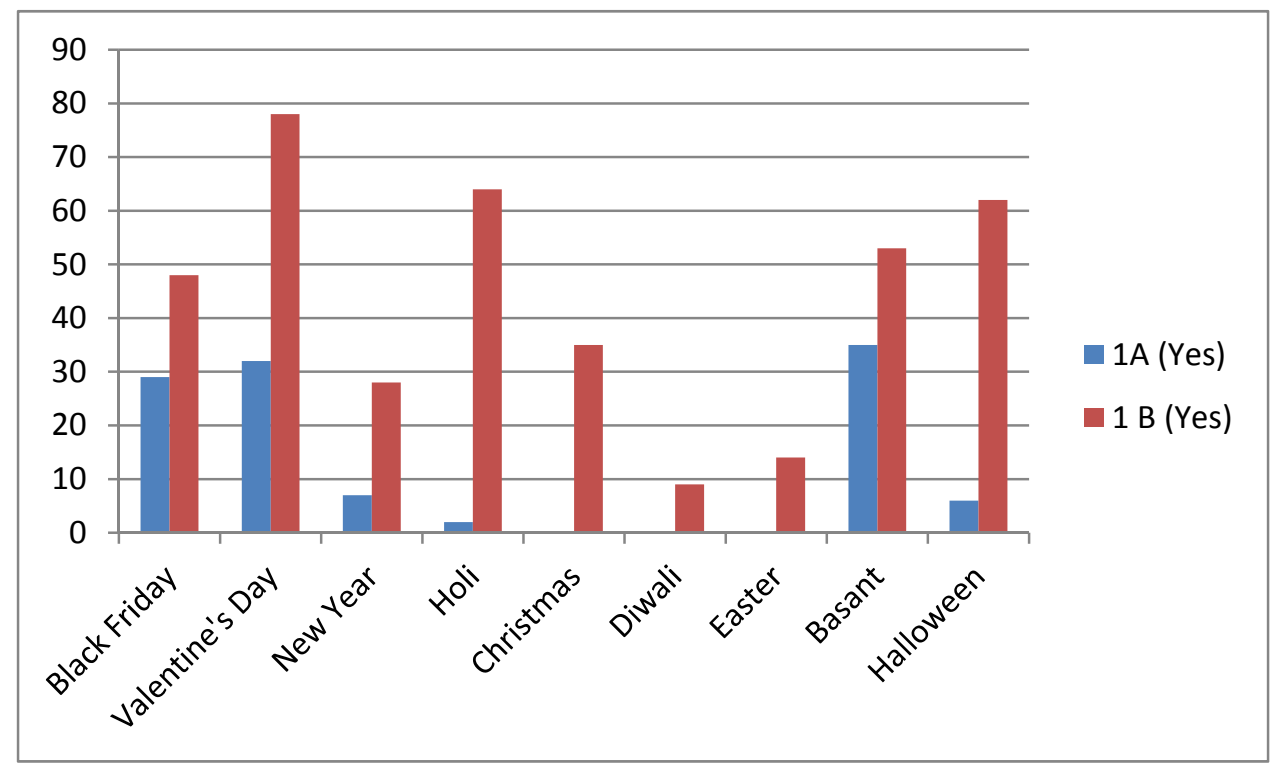

Figure 4. The number of participants belonging to the institutes which celebrate foreign festivals

The data from participants from the same group reflect that "Valentine's Day, "Holi", "Basant" and "Halloween" is celebrated at private institutions.

Table 7. The perceptions of the participants about question 5: Is there any harm in celebrating this day at an individual or national level?

\begin{tabular}{|c|c|c|c|c|c|c|c|c|c|c|c|c|c|c|c|c|c|c|}
\hline & \multicolumn{2}{|c|}{$\begin{array}{l}\text { Black } \\
\text { Friday }\end{array}$} & \multicolumn{2}{|c|}{$\begin{array}{l}\text { Valentine's } \\
\text { Day }\end{array}$} & \multicolumn{2}{|c|}{ New Year } & \multicolumn{2}{|c|}{ Holi } & \multicolumn{2}{|c|}{ Christmas } & \multicolumn{2}{|c|}{ Diwali } & \multicolumn{2}{|c|}{ Easter } & \multicolumn{2}{|c|}{ Basant } & \multicolumn{2}{|c|}{ Halloween } \\
\hline & $\mathrm{Y}$ & $\mathrm{N}$ & $\mathrm{Y}$ & $\mathrm{N}$ & Y & $\mathrm{N}$ & Y & $\mathrm{N}$ & $\mathrm{Y}$ & $\mathrm{N}$ & $\mathrm{Y}$ & $\mathrm{N}$ & $\mathrm{Y}$ & $\mathrm{N}$ & $\mathrm{Y}$ & $\mathrm{N}$ & $\mathrm{Y}$ & $\mathrm{N}$ \\
\hline $1-\mathrm{A}$ & 32 & 68 & 63 & 37 & 69 & 31 & 88 & 12 & 92 & 08 & 92 & 08 & 92 & 08 & 45 & 55 & 79 & 21 \\
\hline $1-B$ & 05 & 95 & 08 & 92 & 11 & 89 & 11 & 89 & 11 & 89 & 11 & 89 & 11 & 89 & 07 & 93 & 11 & 89 \\
\hline
\end{tabular}

Note. $\mathrm{Y}=$ Yes; N=No; Group 1-A (age 13-19yrs, parents' income=up to 60,000/-PKR, studying in public institution); Group 1-B (age 13$19 \mathrm{yrs}$, parents' income=more than $60,000 /$-PKR, studying in private institution).

The findings suggest that participants from public institutions perceive that there is harm in celebrating most of these foreign festivals; however, they do not find any harm in celebrating "Black Friday" and "Basant". On the other hand, most of the participants from private institution see no harm in celebrating any of these festivals. 


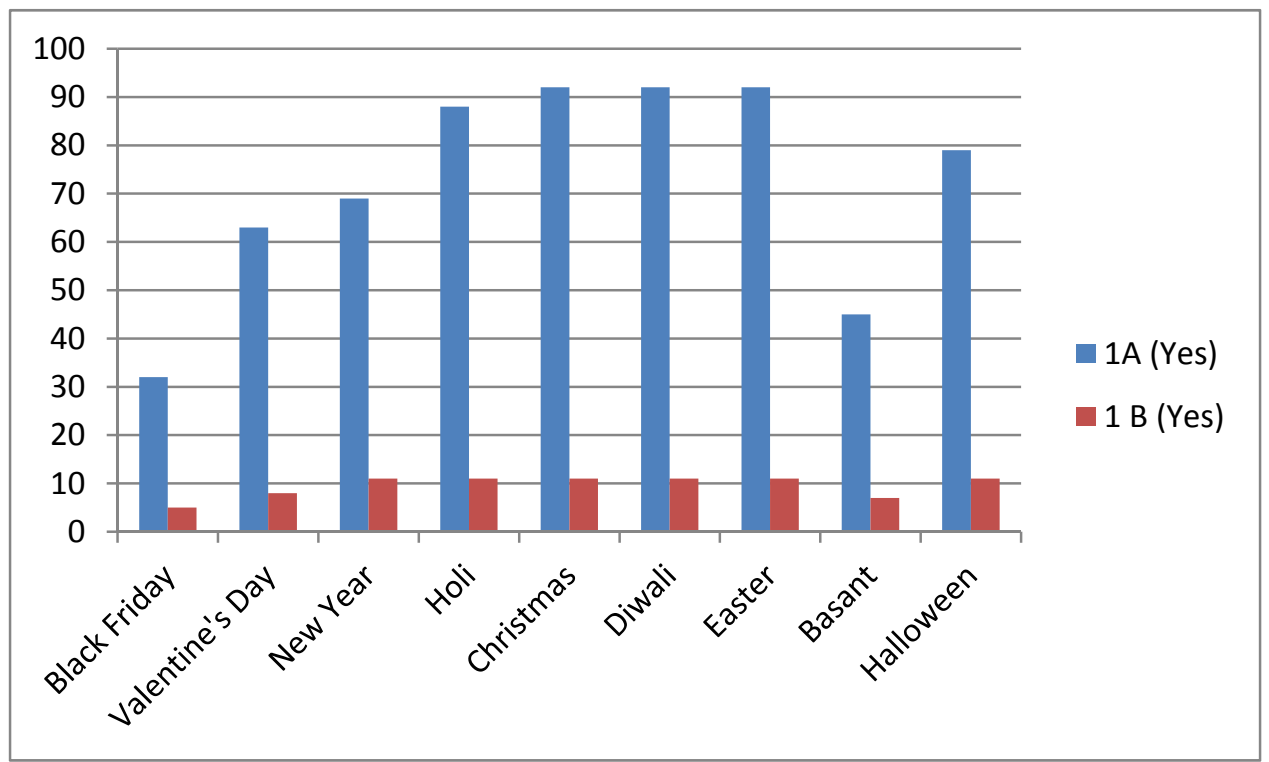

Figure 5. The participants who perceive harm in celebrating foreign festivals

Figure 5 graphically represents the number of participants from both groups who perceive the celebration of these events harmful.

Table 8. The perceptions of the participants about question 6: How did you learn about this festival?

\begin{tabular}{|c|c|c|c|c|c|c|c|c|c|c|c|c|c|c|c|c|c|c|c|}
\hline & \multicolumn{2}{|c|}{$\begin{array}{l}\text { Black } \\
\text { Friday }\end{array}$} & \multicolumn{2}{|c|}{$\begin{array}{l}\text { Valentine's } \\
\text { Day }\end{array}$} & \multicolumn{2}{|c|}{ New Year } & \multicolumn{2}{|c|}{ Holi } & \multicolumn{2}{|c|}{ Christmas } & \multicolumn{2}{|c|}{ Diwali } & \multicolumn{3}{|c|}{ Easter } & \multicolumn{2}{|c|}{ Basant } & \multicolumn{2}{|c|}{ Halloween } \\
\hline & $\mathrm{M}$ & $\mathrm{Fr}$ & $\mathrm{M}$ & $\mathrm{Fr}$ & $\mathrm{M}$ & $\mathrm{Fr}$ & $M$ & I & $\mathrm{M}$ & $\mathrm{Fm}$ & $\mathrm{M}$ & Fm & $\mathrm{M}$ & $\mathrm{Fm}$ & I & $M$ & $\mathrm{Fm}$ & $M$ & I \\
\hline $1-\mathrm{A}$ & 91 & 09 & 74 & 26 & 97 & 03 & 98 & 02 & 42 & 58 & 26 & 74 & 21 & 79 & 00 & 52 & 48 & 60 & 40 \\
\hline $1-B$ & 98 & 02 & 93 & 07 & 98 & 02 & 71 & 29 & 73 & 27 & 88 & 12 & 67 & 00 & 33 & 74 & 26 & 75 & 25 \\
\hline
\end{tabular}

The findings suggest that it is mostly the media, in the case of participants of public institutions, through which teenagers learn about the above-mentioned holidays, whereas the participants of private institutions stated that he awareness of children about certain cultural or religious festivals come from the media as well as well as the educational institutions.

\subsection{Part B}

Following is the presentation of responses gathered through interviews of five participants from each group and a discussion by the researcher. This provided further insight into the matter and the institutional practices (both Public and Private) regarding multicultural festival celebrations.

\subsubsection{Perceptions of the Students Hailing from Public Sector Institutions (Low Income Group)}

The education provided by the state in Pakistan has been categorically rejected by the emerging middle class who, for all possible socio-economic reasons, prefers the private education system. The public sector education, therefore, caters to the educational needs of the low income group or the underprivileged strata of the society. Students from these institutions do not celebrate these foreign festivals as their educational institutions did neither encourage nor create awareness about them. Furthermore, keeping in view the socio-economic background of these students, it is evident that their exposure to digital technology and media was limited, hence showing their limited knowledge and interest in the subject. Mostly, it is the parents, apart from media, who guide their children about the origin of the foreign festivals. They take them as "foreign" and understand that they may pose challenges to the national integrity. Celebration of foreign religious festivals such as "Holi" or "Christmas", is not hailed by them at all. However, most of them find no harm in celebrating "Valentine's Day", thinking that giving a gift to a friend or teacher should not be objectionable. 


\subsubsection{Perceptions of the Students Hailing from Private Sector Institutions (High Income Group)}

Respondents who belong to this group displayed the eagerness to celebrate various festivals. Students were of the opinion that there is no harm in celebrating these festivals as they did not, by any means, harm anyone and merely provided chances to celebrate and be happy. A few believed that it could lead to the dissolution of one's identity and religious values. Furthermore, the views of these students were further reinforced by their educational instruction which made it a point to celebrate some and create awareness regarding all these festivals.

Another trend that emerged from the responses of these students was that, given their levels of prosperity and proficiency in the English language, they had greater opportunities and access to the international world primarily through social media and sometimes through international travelling as well. Hence, the students of this group displayed immense knowledge and willingness to celebrate these festivals.

\section{Conclusion}

Globalization plays an important role in shaping up people's choices, cultural taste, values and to be precise, lifestyles. The multicultural-flow seems quite speedy in Pakistan and impacts different strata of society in various ways. The findings of the study suggest that adolescents who belong to higher social classes and study in private schools whose medium of instruction is English, are quite open to change; they look forward to celebrating these foreign cultural and religious festivals; even most of their parents have shown no negative concerns about the celebrations of these festivals by their children. Most of these festivals are celebrated at their educational institutions and they do not consider celebrating these festivals at individual or national level harmful. The main medium of transfer is, of course, the fact that students who attend private schools have a high level of proficiency in the English language. The source of awareness for them is mostly media or their institutions, which imitate or transfer the culture of the English-speaking countries (globalization). On the other hand, the adolescents who are part of public institutions and belong to lower socio-economic background, whose medium of instruction is the Urdu language, are only interested in celebrating Black Friday, maybe because it is a good chance for them to buy things on sale keeping in mind their parents' income level, "Valentine's day", as it can be celebrated by giving gifts to their institutional friends (same sex) and "Basant", which can celebrated by families together. However, media or family training has been found to be a major source of awareness about these festivals by this group.

The study suggests a need to protect indigenous cultural identity. However, to prevent local nationalism, Pakistani people should propagate their culture through media, thinking about local indigenous values and traditions, instead of being an instrument in the hands of global forces. This study also suggests training the young generation to be open and tolerant to transnational cultures. If Pakistanis do not retain their identity, soon they will be a part of the global culture.

Media is reported as a major source of disseminating cultural diversity, so there is a need to formulate communication policy, with more emphasis on Muslim culture, religion and social values. The study selected the dimension of cultural and religious festivals only in order to highlight the relationship between globalization and culture; there is a need to explore further facets of cultural awareness in this regard.

\section{Acknowledgments}

The researchers are indebted to the support and conducive environment provided by the institutions from which the sample subjects were selected for data collection. No less is the contribution of the teachers and principals of the institutions who facilitated the researchers to get insightful suggestions in implementing the research plan. Thanks is also due to Department of English Language and Literature, University of Management and Technology, Lahore, for the provision of letter to carry out this research and for allowing to set up a project before the drafting of this article. Constructive feedback and suggestion by peers and colleagues also proved invaluable.

\section{References}

Adair, W. L., Okumura, T., \& Brett, J. M. (2001). Negotiation behavior when cultures collide: The United States and Japan. Journal of Applied Psychology, 86(3), 371. https://doi.org/10.1037/0021-9010.86.3.371

Adams, D., \& Goldbard, A. (2009). Glocalization, Mass Media and Multiculturalism: Issues and Concrens-1. Learning media.

Appiah, K. A. (2006). Cosmopolitanism: Ethics in a world of strangers. In N. C. Asuncio-Lande (Ed.), Ethical Perspectives and Critical Issues in Intercultural Communication (pp. 394-399). London: Allen Lane. 
Berelson, B. (1952). Content analysis in communication research. Glencoe: Free Press.

Blanc-Noel, N. (2010). Multicultural Sweden, assimilationist France: how and why national identity narratives evolve. Sens Public. Retrieved from http://sens-public.org/

Chao, M. M., Kung, F. Y., \& Yao, D. J. (2015). Understanding the divergent effects of multicultural exposure. International Journal of Intercultural Relations, 47, 78-88. https://doi.org/10.1016/j.ijintrel.2015.03.032

Chaudhry, Z. (2017). Influence of Hindi dubbed cartoons on the linguistic repertoire of Urdu/English bilingual children. Unpublished M.Phil dissertation, Department of English Language and Literature, University of Management Sciences, Pakistan.

Crowder, G. (2013). Theories of multiculturalism: An introduction. Oxford: Polity.

Derrett, R. (2008). Regional festivals: Nourishing community resilience: the nature and role of cultural festivals in Northern Rivers NSW communities. Theses, 90.

Eisler, D. B. (2005). The logical conclusion: Hamelink's Cultural Autonomy Theory of communication and its implication in Marcos-Era Philippines. Retrieved January 6, 2019, from http://www.austindispatches.com/archives/Paper\%2023.pdf - Google Search. (n.d.).

Frisbie, R. D. (1986). The use of microcomputer programs to improve the reliability and validity of content analysis in evaluation. Annual Meeting of the American Educational Research Association. San Francisco, CA.

Gordon, P. H., \& Meunier, S. (2001). Globalization and French cultural identity. French Politics, Culture \& Society, 19(1), 22-41. https://doi.org/10.3167/153763701782370127

Grant, M. J. (2014). Thirty years of practitioner-based projects. Health Information \& Libraries Journal, 31(1), 1-3. https://doi.org/10.1111/hir.12058

Hamelink, C. J. (1983). Cultural autonomy in global communications: planning national information policy (pp. 22-23). New York City: Longman.

Higham, B. S. (2000). Is multiculturalism cultural imperialism? Retrieved from http://www.academia.edu/24392223/Is_multiculturalism_cultural_imperialism

Hughes, R. (1994). Multi-Culti and its discontents in cultures of complaint. London: Harvill (Harper Collins).

Kaul, V. (2012). Globalisation and crisis of cultural identity. Journal of Research in International Business and Management, 2(13), 341-349.

Kayani, A. K., Ahmad, K., \& Saeed, A. (2013). Perceptions about Cultural Globalization in Urban Pakistan. South Asian Studies, 28(1).

Keaney, M. (2002). Unhealthy accumulation: the globalization of health care privatization. Review of Social Economy, 60(3), 331-357. https://doi.org/10.1080/0034676021000013430

Kerimova, G. (2009). Globalization and cultural identity: Azerbaijan's case. Journal of Azerbaijani Studies, 12(4), 73-88.

Khan, A. M., \& Arif, I. (2009). Media imperialism and its effects on culture of Pakistan, a case study of youth of Multan. Global Media Journal, 2(1).

Krzysztofek, K. (2002). Global governance, global culture, and multiculturalism. Canadian Journal of Communication, 27(2). https://doi.org/10.22230/cjc.2002v27n2a1302

Maddux, W. W., \& Galinsky, A. D. (2009). Cultural borders and mental barriers: The relationship between living abroad and creativity. Journal of Personality and Social Psychology, 96(5), 1047. https://doi.org/10.1037/a0014861

Maldonado Garcia, M. I. (2015). A corpus based quantitative survey of the English elements in the basic vocabulary of urdu language. International Journal of Humanities and Social Science, 5(4), 29-36

Maldonado Garcia. M. I. (2016). Reforming the national curriculum. Teaching the national and provincial languages of Pakistan. Journal of Elementary Education, 25(2), 73-87.

Matos, C. (2012). Globalization and the mass media. Oxford: Wiley-Blackwell.

Mustafa, M. T., Mushtaq, S., Malik, B. M., \& Abbas, M. R. S. N. (2015). Cultural Islam: Keeping Faith and Tradition under Indian Culture in Pakistan. Journal of Policy Research, 1(4), 156-163. 
Naz, A., Khan, W., Daraz, U., \& Hussain, M. (2012). The Crises of identity: Globalization and its impacts on socio-cultural and psychological identity among Pakhtuns of Khyber Pakhtunkhwa Pakistan. International Journal of Academic Research in Business and Social Sciences, 1(1), 1-11. https://doi.org/10.2139/ssrn.2082990

Ornek, Y. (2007). Globalization and Cultural Identity (pp. 83-88). The proceedings of the Twenty-first world congress of Philosophy, 13. https://doi.org/10.5840/wcp2120071312

Rattansi, A. (2011). Multiculturalism: A very short introduction. OUP Oxford. https://doi.org/10.1093/actrade/9780199546039.001.0001

Raza, S., Awan, S., \& Gondal, S. (2016). What are Your Children Watching? Teacher's Evaluation of the Educational, Emotional, Behavioral, Psychological, Physical \& Religious Impacts of Cartoons on the School Going Children. Journal of Philosophy, Culture and Religion, 22, 39-45.

Saddiqa, A. (2017). Phonological impact of Hindi cartoons on the speech of Urdu/English bilingual children. (Unpublished M.Phil Dissertation). University of Management and Technology, Lahore, Pakistan.

Sezer, D. (2016). The influence of cartoon movies on children's progress. - Google Search. (n.d.). Retrieved January

6 , 2019 ,

from https://www.google.com/search?ei=8VUyXNz0A6XMxgPw962IBw\&q=Sezer\%2C+D.+\%282016\%29.+Th e + influence + of + cartoon + movies + on + children $\%$ E $\% 80 \% 99 \mathrm{~s}+$ progress. $+\&$ oq $=$ Sezer $\% 2 \mathrm{C}+\mathrm{D} .+\% 282016 \% 2$ 9. + The + influence + of + cartoon + movies + on + children $\%$ E2\% $\% 0 \% 99 \mathrm{~s}+$ progress. $+\& g s \_$l $=$psy-ab.3 ...7297.1180 3..12518...0.0..0.221.875.2-4......0....1...gws-wiz.YrgvOXLTuEc

Sohail, H. (2015). Effects of Westernization on the culture of Pakistan. Retrieved January 6, 2019, from https://owlcation.com/social-sciences/Effects-of-Westernization-on-the-culture-of-Pakistan-GoogleSearch(n .d.)

Tadmor, C. T., Satterstrom, P., Jang, S., \& Polzer, J. T. (2012). Beyond individual creativity: The superadditive benefits of multicultural experience for collective creativity in culturally diverse teams. Journal of Cross-Cultural Psychology, 43(3), 384-392. https://doi.org/10.1177/0022022111435259

Yousaf, A. (2013). Impact of Globalization on culture. Retrieved January 6, 2019, from https://www.musero.org.ng/publications/impact_globalization_culture.pdf-GoogleSearch.(n.d.)

\section{Copyrights}

Copyright for this article is retained by the author, with first publication rights granted to the journal.

This is an open-access article distributed under the terms and conditions of the Creative Commons Attribution license (http://creativecommons.org/licenses/by/4.0/). 